\title{
Management and treatment of glomerular diseases (part 1): conclusions from a Kidney Disease: Improving Global Outcomes (KDIGO) Controversies Conference

Jürgen Floege ${ }^{1}$, Sean J. Barbour 2,3,4, Daniel C. Cattran ${ }^{5}$, Jonathan J. Hogan ${ }^{6}$, Patrick H. Nachman, Sydney C.W. Tang ${ }^{8}$, Jack F.M. Wetzels ${ }^{9}$, Michael Cheung ${ }^{10}$, David C. Wheeler ${ }^{11}$, Wolfgang C. Winkelmayer ${ }^{12}$ and Brad H. Rovin ${ }^{13}$; for Conference Participants ${ }^{14}$

${ }^{7}$ Division of Nephrology, Rheinisch-Westfälische Technische Hochschule University of Aachen, Aachen, Germany; ${ }^{2}$ British Columbia Provincial Renal Agency, Vancouver, British Columbia, Canada; ${ }^{3}$ Division of Nephrology, University of British Columbia, Vancouver, British Columbia, Canada; ${ }^{4}$ Centre for Health Evaluation and Outcomes Research, St. Paul's Hospital, Vancouver, British Columbia, Canada; ${ }^{5}$ Toronto General Research Institute, University Health Network, Toronto, Ontario, Canada; ${ }^{6}$ Division of Nephrology, University of Pennsylvania, Philadelphia, Pennsylvania, USA; ${ }^{7}$ Division of Renal Diseases and Hypertension, University of Minnesota, Minneapolis, Minnesota, USA; ${ }^{8}$ Department of Medicine, The University of Hong Kong, Queen Mary Hospital, Hong Kong, China; ${ }^{9}$ Department of Nephrology, Radboud University Medical Center, Nijmegen, The Netherlands; ${ }^{10} \mathrm{KDIGO}$, Brussels, Belgium; ${ }^{11}$ University College London, London, UK; ${ }^{12}$ Selzman Institute for Kidney Health, Section of Nephrology, Department of Medicine, Baylor College of Medicine, Houston, Texas, USA; and ${ }^{13}$ Division of Nephrology, The Ohio State University, Wexner Medical Center, Columbus, Ohio, USA

The Kidney Disease: Improving Global Outcomes (KDIGO) initiative organized a Controversies Conference on glomerular diseases in November 2017. The conference focused on the 2012 KDIGO guideline with the aim of identifying new insights into nomenclature, pathogenesis, diagnostic work-up, and, in particular, therapy of glomerular diseases since the guideline's publication. It was the consensus of the group that most guideline recommendations, in particular those dealing with therapy, will need to be revisited by the guideline-updating Work Group. This report covers general management of glomerular disease, IgA nephropathy, and membranous nephropathy.

Kidney International (2019) 95, 268-280; https://doi.org/10.1016/ j.kint.2018.10.018

KEYWORDS: hypertension; IgA nephropathy; KDIGO; kidney biopsy; membranous nephropathy; proteinuria

Copyright ( ) 2019, The Author(s). Published by Elsevier Inc. on behalf of the International Society of Nephrology. This is an open access article under the CC BY-NC-ND license (http://creativecommons.org/licenses/by-nc-nd/4.0/).

Correspondence: Jürgen Floege, Division of Nephrology and Clinical Immunology, Rheinisch-Westfälische Technische Hochschule University of Aachen, Pauwelsstrasse 30, 52057 Aachen, Germany. E-mail: jlloege@ukaachen.de, or Brad H. Rovin, Division of Nephrology, The Ohio State University, Wexner Medical Center, 395 West 12th Avenue, Ground Floor, Columbus, Ohio 43210, USA. E-mail: rovin.1@osu.edu

${ }^{14}$ See Appendix for list of other Conference Participants.

Received 26 June 2018; revised 10 October 2018; accepted 24 October 2018
The Kidney Disease: Improving Global Outcomes (KDIGO) initiative published its first guideline on glomerular diseases in 2012..$^{1}$ Given the enormous advances in understanding the pathogenesis of glomerular diseases, identification of new diagnostic biomarkers, and emerging therapies, about 100 experts from various disciplines (nephrology, pathology, rheumatology, pediatrics) and organizations (academia, pharmaceutical industry) convened on November 17-19, 2017. Through plenary and small group discussions, the conference aimed to evaluate consensus and controversies in nomenclature, general work-up and management of glomerular diseases, future needs in research, and, in particular, the critical assessment of existing guideline recommendations.

This first of 2 reports covers general management of glomerular diseases. In addition, this report addresses 2 common forms of glomerulonephritis (GN), namely IgA nephropathy (IgAN) and membranous nephropathy. Primary podocytopathies, complement-mediated glomerular diseases, lupus nephritis, antineutrophil cytoplasmic antibodyassociated nephritis, and monoclonal gammopathies of renal significance will be covered in the second report. These 2 conference summaries will lay the basis for the guideline updating process that began in August 2018.

\section{GENERAL PRINCIPLES IN THE MANAGEMENT OF GLOMERULAR DISEASE}

This section will consider newer concepts and controversies in the general management principles of glomerular disorders. Disease-specific issues, applications, or exceptions to these general statements will be discussed within each of the individual glomerular disease sections. Additional broad-based management principles for glomerular diseases may be 
found in chapter 2 of the 2012 KDIGO Clinical Practice Guideline for Glomerulonephritis. ${ }^{1}$

\section{Kidney Biopsy}

The kidney biopsy remains the cornerstone for the evaluation of glomerular disease. ${ }^{2,3}$ In very few and specific circumstances such as childhood steroid-sensitive nephrotic syndrome, diagnosis and treatment are often done without a kidney biopsy. In adults this approach is uncommon but may be considered in individual cases. For example, patients who have normal kidney function, acute onset of nephrotic syndrome, and are positive for anti-phospholipase A2 receptor (PLA2R) antibodies are likely to have membranous nephropathy. Treatment could be initiated without biopsy if such patients had a high risk of procedural complications, but care must be taken as other diseases may emulate all of these features. ${ }^{4,5}$

Kidney tissue is also critical for assessing the degree of histologic activity and chronicity and to identify unexpected features such as interstitial nephritis, acute kidney injury, and crescents, all factors that might significantly impact disease management.

The kidney biopsy should be interpreted in the context of ethnicity, age, and hypertension, as these may modify the background kidney histology. For instance, understanding the "normal" range of age-related focal segmental glomerulosclerosis in a population might allow a better estimate of the extent of glomerular disease in an individual biopsy. ${ }^{6}$ Application of other modifiers, such as ethnicity, needs to be considered.

The value of kidney tissue is likely to expand significantly in the near term. It is likely that taking a more system-related approach to the biopsy will enhance its value by providing more information important to diagnosis, prognosis, and treatment. For example, all clinical trials have treatment failures suggesting variations between individuals in the molecular pathways driving disease progression despite similar histopathology. To develop targeted therapies, identification of these pathways is necessary and will require a focus on mechanisms operative at the tissue level rather than relying solely on standard histologic findings. This also ties into the new concept of immunologic versus clinical remission. ${ }^{5,7,8}$

The need for electron microscopy for every biopsy remains controversial. It can be critical in some cases, for example, to differentiate between immunologically mediated and adaptive focal segmental glomerulosclerosis variants. ${ }^{9}$ Application at a worldwide level may be difficult, but it could possibly be leveraged by preservation of a small amount of tissue and, if judged critical to management, sent to an electron microscopy reference laboratory for evaluation.

\section{Assessment of kidney function}

Proteinuria. Most glomerular diseases are associated with significant proteinuria. Although ratios of albumin-tocreatinine or protein-to-creatinine (PCR) in random spot urines are commonly used, recent data highlight the poor agreement between these ratios and 24-hour urine protein measurements. ${ }^{10}$ Although spot albumin-to-creatinine ratio and PCR are helpful in general clinical management, they are not sufficiently accurate when therapeutic decisions about using high-risk medications are being made on small changes in proteinuria. ${ }^{11,12}$ In such cases, a 24 -hour urine protein or PCR should be measured. Importantly, the PCR from an intended 24-hour urine collection that is at least 50\% complete has been shown to accurately reflect 24-hour proteinuria. $^{13}$

In young children, obtaining a 24-hour urine collection is usually not possible and PCR is the preferred means to assess proteinuria. Monitoring serum albumin levels in nephrotic patients also represents a valuable tool to indirectly assess the extent of proteinuria.

GFR assessments. The gold standard for estimating renal excretory function remains inulin or isotopic clearance techniques, but these are expensive and require operator expertise. Newer, accurate techniques to measure glomerular filtration rate (GFR) are evolving. ${ }^{14}$ Presently, the Chronic Kidney Disease Epidemiology Collaboration's (CKD-EPI) equation for estimating GFR is often used instead. ${ }^{15}$ Formulas have also been developed for children. ${ }^{16,17}$ However, estimated GFR (eGFR) equations have not been validated in specific glomerular diseases and patient populations. In addition, when estimating glomerular function in patients with high-grade proteinuria, the majority of studies still use 24-hour urine collections for creatinine clearance. Errors related to collection and laboratory measurements under these conditions can induce up to $50 \%$ of errors in GFR measurement. ${ }^{18-20}$ The accuracy of these methods may be partially compensated by frequent longitudinal measurement and use of data-smoothing techniques. ${ }^{21}$ A simple, reliable, and inexpensive biomarker of kidney function is still wanting.

Hematuria. Macro- or microhematuria is associated with almost all glomerular disorders and identification of red cell casts may provide clues to nephritic diseases such as IgAN. Qualitatively, the routine urine dipstick can distinguish the presence or absence of microhematuria, but the capacity to quantitate hematuria has pitfalls, including timing between collection and examination, urine concentration, preparation of the urine pellet, $\mathrm{pH}$ of the urine, and the expertise of the examiner. The disappearance of hematuria, however, associated with complete clinical remission can be important in assessing the activity of diseases such as IgAN and antineutrophil cytoplasmic antibody vasculitis. ${ }^{22,23}$

Outcome measures. Regulatory agencies still grant approval for drugs in GN based on the classic findings of complete remission of proteinuria, as a positive outcome, and end-stage kidney disease (ESKD) (or a 50\% reduction in eGFR), and/or mortality as negative outcomes. Recent collaborations among the US Food and Drug Administration, the pharmaceutical industry, and members of nephrology organizations, under the umbrella organization, the Kidney Health Initiative, are developing alternative surrogate endpoints for drug approval. The first consensus meeting 
culminated in a decision to allow a $40 \%$ reduction in eGFR to serve as an endpoint, but earlier endpoints are needed in these rare diseases. ${ }^{24}$ In membranous nephropathy, recent data suggest that complete remission could serve as a surrogate endpoint and partial remission used as a basis for approval under the accelerated approval program in the United States. ${ }^{25}$ Both outcomes are supported by statistical techniques that allow the prospective quantitation of the benefit of a partial remission of proteinuria based on its duration in an individual patient. ${ }^{26}$ The Kidney Health Initiative group is currently evaluating surrogate endpoints in IgAN and lupus nephritis.

Futility. The concept of futility can be critical to patient management. This "point of no return" is usually defined by a low eGFR, often $<30 \mathrm{ml} / \mathrm{min}$ per $1.73 \mathrm{~m}^{2}$ and/or kidney biopsy that shows a high degree of irreversible chronic changes. ${ }^{1}$ Noninvasive assessment of whole kidney chronicity/ fibrosis is not ready for clinical application. ${ }^{27}$ Currently, the rate of change in kidney function is likely more important than a single cross-sectional measurement of eGFR in defining futility. Additionally, age and overall wellness should be considered when determining futility.

The question of futility also extends to clinical trials. Futility criteria are often used to exclude patients from clinical trials with the thought that risk will outweigh gain for such patients. Therefore, many patients miss the opportunity to participate in trials, complicating attainment of sample size and generalizability of results. It may be helpful to have more patient engagement in determining clinical trial eligibility. If the treating physician thinks it is reasonable to consider a clinical trial and their patient is fully informed, such patients could be considered if futility criteria were less rigid. This concept is commonly followed in clinical practice. Although controversial, patient engagement may become more relevant as low-risk treatments become available.

\section{Quality of life and quality of health}

Quality of life and health are important components of determining treatment value and are increasingly used by regulatory agencies to assess overall worth of a new treatment. ${ }^{1}$ In glomerular diseases, patient-related outcomes and patient-related outcome measurements are evolving, but standards for clinical practice guidelines do not yet exist.

\section{Other determinants of progression of kidney disease}

In addition to well-established progression factors such as persistent proteinuria, poorly controlled hypertension or diabetes, smoking, or widespread cardiovascular disease, ${ }^{28}$ new evidence supports prematurity as having an impact on nephron endowment and potentially limiting renal reserve and increasing risk of progression in glomerular diseases (Table 1). ${ }^{29}$ This can be approximated by birth weight, a readily available, low-cost demographic. Its value within specific diseases is still speculative, but it could be considered as basic information that may affect treatment and outcomes of glomerular diseases.
Another recently defined health risk factor is sleep hygiene. From the National Health and Nutrition Examination Survey in the CKD population, low-sleep duration and other related disorders (e.g., restless legs syndrome, sleep apnea) were associated with all-cause mortality and cardiovascular mortality. Extrapolation into the glomerular disease population seems relevant as this is a modifiable factor and can be applied broadly to all patients. ${ }^{30}$

Weight reduction in obese patients may benefit glomerular diseases. ${ }^{31-33}$ Small studies, focusing on diet and bypass surgery, have shown at least short-term benefits. Weight reduction and sleep improvement are intriguing possible additions to standard treatment approaches that are economical, widely applicable, and that foster patient engagement.

Sex is another issue that is often considered to be an important part of disease risk stratification in GN. Recent data, however, suggest that different rates of progression are more driven by the histologic category, blood pressure (BP), and severity of proteinuria than by sex. ${ }^{34}$

\section{Genetic testing in kidney disease}

Genetic testing has rapidly evolved and its role has expanded to include not only confirming clinical diagnoses, but also establishing inheritance patterns, differentiating heterogeneous disorders, determining appropriate treatment, guiding decisions about family planning, and determining the cause of unexplained familial kidney disorders. It is also expected to be used for identifying new risk factors for susceptibility and progression. Currently cost and unclear clinical implications limit the use of genetic testing. ${ }^{35,36}$

\section{Management of complications of glomerular diseases}

Hypertension. Hypertension control remains crucial to the management of GN. Although some controversy remains, data support a BP target of $125 / 75 \mathrm{~mm} \mathrm{Hg}$ in the GN patient with proteinuria $>1 \mathrm{~g} / \mathrm{d}$. Critical to the management of resistant hypertension is a careful review of the patient's dietary sodium intake. Educating the patient on how to interpret food labels and providing feedback by assessing sodium intake with 24-hour urine sodium estimates are effective strategies. $^{37,38}$ Sodium restriction will not only lower BP, but may enhance the antiproteinuric effects of renin-angiotensin system (RAS) blockers. The Institute of Medicine currently recommends limiting dietary sodium to $<1500 \mathrm{mg} / \mathrm{d}$ (65 $\mathrm{mmol} / \mathrm{d}$ ), which is a $50 \%$ to $75 \%$ reduction from the average North American intake. There are no clear data on optimal sodium restriction in children.

Proteinuria reduction. Proteinuria reduction remains a goal in virtually all glomerular diseases. The main approach is through RAS blockade. An area of controversy is whether angiotensin-converting enzyme inhibitors or angiotensin receptor blockers should be used alone, as dual therapy and/or in combination with an aldosterone antagonist. Previously, hyperkalemia and acute kidney injury outweighed benefits of dual therapy, but recent studies indicate that with careful monitoring, combination therapy can be safe. ${ }^{39}$ Nonetheless, 


\section{Table 1 | Established and emerging risk factors for progression of kidney disease}

\begin{tabular}{ll}
\hline Risk factors for progressive loss of GFR & \multicolumn{1}{c}{ Emerging risk factors for progressive loss of GFR } \\
\hline - Persistent proteinuria & - Prematurity (low birth weight) and other reasons for low nephron number ${ }^{29}$ \\
- Poorly controlled hypertension & - Low-sleep duration and other related disorders (e.g., restless legs syndrome, sleep apnea) ${ }^{30}$ \\
- Poorly controlled diabetes mellitus & - Obesity ${ }^{31-33}$ \\
- Smoking & - Gender? \\
- Widespread cardiovascular disease & \\
- Use of nephrotoxic drugs & \\
\hline
\end{tabular}

GFR, glomerular filtration rate.

the benefit for dual RAS blockade in GN with high-grade proteinuria is not clear. ${ }^{39}$ A practical approach to ameliorating risks due to RAS blockers, particularly acute kidney injury, is by providing "sick day instructions" to withhold or decrease the dose of these medications during periods when volume depletion may occur, as with vomiting or diarrhea.

Aldosterone blockade reduces cardiovascular mortality in patients with heart failure and also reduces albuminuria. ${ }^{40-42}$ However, the absolute risk-benefit ratio for aldosterone blockade in GN remains unclear.

The sodium-glucose transport proteins 2 (SGLT2) inhibitors may offer a new proteinuria reduction strategy. However, in a recent study, short-term treatment with the SGLT2 inhibitor dapagliflozin did not modify renal hemodynamic function or attenuate proteinuria in nondiabetic humans with focal segmental glomerulosclerosis, possibly because of downregulation of renal SGLT2 expression in focal segmental glomerulosclerosis. ${ }^{43}$ Several large studies are currently investigating SGLT2 inhibitors in nondiabetic CKD (e.g., The Study of Heart and Kidney Protection With Empagliflozin [EMPA-KIDNEY], NCT03594110; Effects of Dapagliflozin in Nondiabetic Patients With Proteinuria [DIAMOND], NCT03190694; A Study to Evaluate the Effect of Dapagliflozin on Renal Outcomes and Cardiovascular Mortality in Patients With Chronic Kidney Disease [DapaCKD], NCT03036150).

Hyperlipidemia. The accelerated vascular disease seen in patients with CKD includes those with GN, and recent data suggest this may be worse in some glomerular diseases than others. ${ }^{44,45}$ Although traditionally statins have been used to treat hyperlipidemia and are effective, target values may not be achieved, especially in the new era of very low target lowdensity lipoprotein levels. Novel powerful agents such as proprotein convertase subtilisin/kexin type 9 inhibitors (e.g., evolocumab, alirocumab) need to be studied in the GN population. ${ }^{46}$ Evidence that lipid-lowering therapy in children is beneficial is of poor quality but needs to be explored given their expected longevity. ${ }^{47}$ In contrast to cardiovascular benefits of statins, renal benefits are not well established. ${ }^{48}$

Hypercoagulability. Concerning the risk-benefit ratio of prophylactic anticoagulation in nephrotic patients, especially in those with glomerular diseases associated with thrombotic events, decision aids are available online particularly for patients with membranous nephropathy (www.med.unc.edu/ gntools). ${ }^{49,50}$ Whether non-vitamin-K antagonist oral anticoagulants can be safely used has only been demonstrated above an eGFR of $30 \mathrm{ml} / \mathrm{min}$ per $1.73 \mathrm{~m}^{2}$. Effects of more severe CKD and proteinuria on non-vitamin- $K$ antagonist oral anticoagulant metabolism and clearance require further study. ${ }^{51}$

Risk of infection. There is a risk of infection with most of the medications used to treat the glomerular diseases, including common infections, in particular pneumonias, but also more specific infectious complications such as hepatitis B virus reactivation during immunosuppression ${ }^{52}$ or infections that cluster in particular regions, such as pneumocystis infections in Chinese patients. ${ }^{12}$ Thus, antimicrobial prophylaxis is needed as per regional practice. Specific infections are also more common with certain drugs, such as infection with encapsulated organisms during treatment with the complement inhibitor eculizumab. All patients who will be given this therapy should receive meningococcal vaccination with the multicomponent serogroup B vaccine, ${ }^{1,53}$ beginning at least 2 weeks before starting treatment. This is likely to become more relevant in GN patients as specific complement inhibitors are evaluated for C3 nephropathy and IgAN.

From a global perspective there is also the additional need for careful evaluation of a patient's potential for endemic infections such as tuberculosis, hepatitis B, and parasites based on geographic origins.

\section{Future studies}

Important areas of future research, aside from those mentioned previously, include better and more rapid point-of-care methods (e.g., for GFR, proteinuria, risk evaluations). Indepth collaboration among pathologists, pharmacists, nurses, and clinicians is essential. ${ }^{54}$ Accelerating new drug development coupled with more sophisticated and efficient treatment trials is critical to improving success. For example, cluster and adaptive design methods can shorten trial time, reduce sample size, and accelerate early development. ${ }^{54,55}$

Glomerular diseases are rare but represent a significant percentage of the ESKD population and are one of the few categories of kidney disease that are treatable. The majority have slowly progressive courses, so to reach the outlined goals, we need more specialized GN centers to acquire the necessary sample size cohorts for clinical trials. A GN center (hub) associated with several peripheral units (spokes) is one useful design for connecting with patient advocacy groups and sharing vital information across registries/biobanks. ${ }^{56,57}$ In addition, glomerular disease experts, advocacy groups, and the pharmaceutical industry should be collaborating at all 


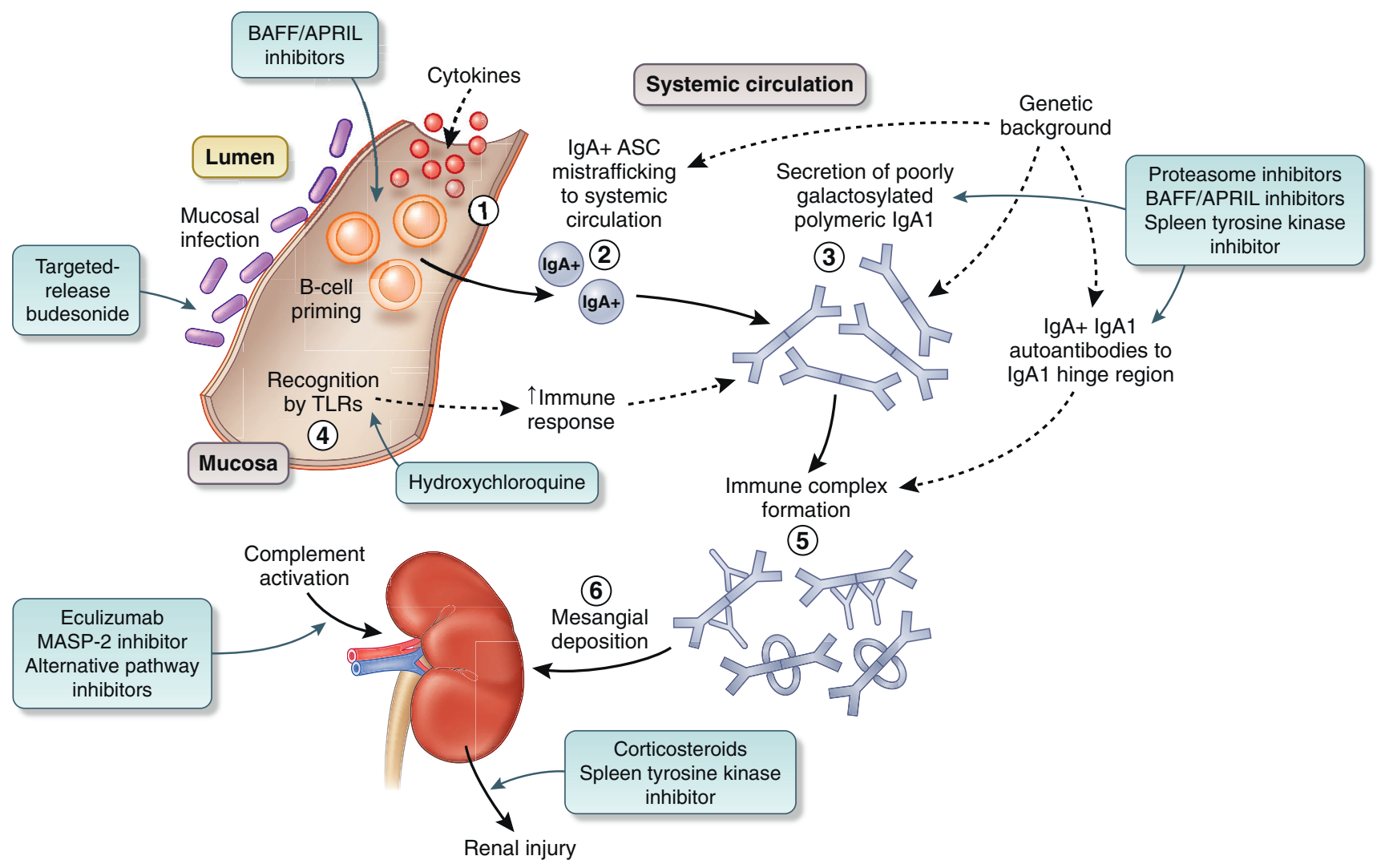

Figure 1 | Proposed pathogenesis of IgA nephropathy (IgAN) and potential therapeutic targets. (1) Mucosal infection primes naive B cells to class switch to become lgA antibody-secreting cells (ASCs) through both T-cell-dependent (cytokine mediated) and T-cell-independent (Tolllike receptor [TLR] ligation) pathways. (2) Some IgA ASCs mis-home to the systemic compartment during lymphocyte trafficking. (3) Displaced IgA+ ASCs take up residence in systemic sites and secrete normal "mucosal-type" (poorly galactosylated and polymeric) IgA1 into the systemic circulation. (4) IgA1 secretion by displaced mucosal ASC is augmented by TLR ligation from mucosal-derived pathogen-associated molecular patterns, which have entered the systemic compartment. (5) IgA1 immune complexes form in the systemic circulation. Poorly galactosylated polymeric IgA1 molecules are the substrate for immune complex formation and combine with $\lg \mathrm{G}$ and $\lg \mathrm{A}$ autoantibodies reactive to exposed neoepitopes in the poorly galactosylated $\operatorname{lgA} 1$ hinge region. (6) $\lg \mathrm{A} 1 \mathrm{immune}$ complexes deposit in the mesangium through a combination of mesangial trapping and increased affinity of poorly galactosylated IgA1 for extracellular matrix components. Immune complex deposition triggers a series of downstream pathways, including complement activation via the mannose-binding lectin and other pathways, leading to glomerular injury and tubulointerstitial scarring. APRIL, a proliferation-inducing ligand; BAFF, B-cell activating factor; MASP-2, mannan-binding lectin-associated serine protease-2. Adapted from Boyd JK, Cheung CK, Molyneux K, et al. An update on the pathogenesis and treatment of IgA nephropathy. Kidney Int. 2012;81:833-843, ${ }^{58}$ with permission. Copyright (c) 2012 International Society of Nephrology.

phases of development to improve investigative strategies, determine best trial designs, and assist in their execution.

\section{IgA NEPHROPATHY Pathogenesis}

New information concerning the pathogenesis of IgAN has become available (Figure 1$)^{58}$ :

- Poorly O-galactosylated IgA1 produced at mucosal surfaces and its increased serum levels in IgAN likely reflect a defective mucosal immune system. ${ }^{59}$ Poorly O-galactosylated IgA1 and circulating autoantibodies to galactose-deficient IgA1 have been reported to predict progression, ${ }^{60}$ but their value in prognostication or disease monitoring has not been properly tested when considered in addition to blood pressure, eGFR, proteinuria, or the MEST-C score-mesangial (M), endocapillary (E) hypercellularity, segmental sclerosis (S), interstitial fibrosis/tubular atrophy (T), crescents (C) (see Biomarkers and prediction of prognosis). Similarly, using a novel antibody-based assay, serum levels of poorly Ogalactosylated IgA1 were not sufficiently discriminatory to warrant its use as a diagnostic or prognostic tool. ${ }^{61} \mathrm{~A}$ recent genome-wide association study in IgAN identified susceptibility gene loci involved in intestinal mucosal immunity. ${ }^{62}$ In support, the Effect of Nefecon in Patients With Primary IgA Nephropathy at Risk of Developing End-stage Renal Disease (NEFIGAN) trial, which targeted budesonide to the distal ileum, reduced proteinuria in patients with IgAN after 9 months of treatment. ${ }^{63}$ A confirmatory phase 3 trial is currently underway.

- Mucosal activation of the innate immune response through ligation of Toll-like receptors (TLR) engagement by microbes and other danger signals, and signaling through the B-cell survival factors B-cell activating factor and a proliferation inducing ligand are critical events regulating 
mucosal immunity, and are targets for therapeutic intervention with hydroxychloroquine or B-cell activating factor/a proliferation inducing ligand inhibitors. ${ }^{64-66}$

- Glomerular injury in IgAN is associated with activation of the complement system. ${ }^{67,68}$ This is supported by genetic mapping and clinical reports of eculizumab rescuing crescentic IgAN. ${ }^{68-70} \mathrm{~A}$ monoclonal antibody targeting mannan-binding lectin-associated serine protease 2, the effector enzyme of the lectin pathway, has shown antiproteinuric effects in 4 IgAN patients, and a phase 3 trial is now underway. ${ }^{71}$ Although these pathogenic mechanisms have resulted in novel therapeutic possibilities, further evidence from larger long-term trials is required before they can be included in future guideline recommendations.

\section{Biomarkers and prediction of prognosis}

The MEST scoring system for IgAN offered the first opportunity to use histology to predict renal outcome independent of proteinuria, BP, and eGFR. ${ }^{72,73}$ The European Validation Study of the Oxford Classification of IgAN (VALIGA) study confirmed the association of M1, S1, and T1/2 with renal outcomes, and the association of M1 and E1 with subsequent increase in proteinuria. ${ }^{74}$ In children, MEST scoring yielded a higher prevalence of proliferative lesions versus sclerotic lesions. ${ }^{74}$ When the MEST score in adults was combined with eGFR, proteinuria, and BP at biopsy, it was possible to predict renal outcome with the same accuracy as clinical data over 2 years of follow-up, and thereby the MEST score allowed risk stratification at an earlier time point. ${ }^{75} \mathrm{~A}$ large analysis of IgAN patients demonstrated that cellular or fibrocellular crescents were independently associated with a higher risk of kidney disease progression, especially in those not immunosuppressed. ${ }^{76}$ In addition, crescents in $>25 \%$ of glomeruli were associated with an increased risk of poor renal outcome even in patients treated with immunosuppression, although this was based on small subgroups and the results were not consistent across all outcomes evaluated. ${ }^{76}$ Based on this study, MEST now includes a C score of 1 or 2 (crescents $<25 \%$ or $>25 \%$, respectively). Importantly, MEST-C score was developed to predict renal outcome and not to guide treatment or to predict treatment response. Although observational data suggest that E1 and crescents may predict outcomes differently in treated versus untreated patients, and the benefits of steroids may differ in patients with $\mathrm{M} 1$ or $\mathrm{S} 1$, there is currently insufficient evidence to suggest that immunosuppression decisions should be based on histology parameters. ${ }^{72,76-78}$ A major limitation is the absence of a validated risk prediction model that allows integration of histology with clinical predictors to establish an accurate individual prognosis.

New biomarkers are needed to further improve prediction of renal prognosis in IgAN. Glomerular C4d deposition may represent a marker of an adverse prognosis, ${ }^{79}$ but this finding needs more external validation before it can be routinely recommended. A small study demonstrated an association between time-averaged microhematuria $>5$ red blood cells per high-power field and the risk of ESKD especially when combined with time-averaged proteinuria. ${ }^{23}$ However, time-averaged values require the entire duration of follow-up, which is not clinically relevant, and it is not clear whether the association is independent of MEST-C and other established clinical predictors.

There have been over 1000 derivation studies for biomarkers in IgAN. To date, none have externally validated the assay reproducibility and association with renal outcome using commercially available platforms, and none have translated the results into clinical practice by demonstrating that the biomarker improves prediction beyond other readily available risk factors. ${ }^{80}$ Currently, no biomarker is ready for clinical application.

\section{Treatment}

Significant controversy surrounds the use of steroids in IgAN. The Supportive Versus Immunosuppressive Therapy for the Treatment of Progressive IgA Nephropathy (STOP-IgAN) trial randomized patients to supportive treatment, or to steroids alone, or steroids in conjunction with sequential cyclophosphamide and azathioprine based on eGFR. Immunosuppression transiently reduced proteinuria over 3 years but had no impact on eGFR and only resulted in significant, particularly, infectious adverse events. ${ }^{81}$ Proteinuria reduction occurred mostly in the steroid and not immunosuppressive combination therapy group. ${ }^{82}$ Optimized supportive treatment was associated with a very slow loss of kidney function in the control group, so that the study was underpowered to detect eGFR-based outcomes. The Therapeutic Evaluation of Steroids in IgA Nephropathy Global Study (TESTING Low Dose Study) (TESTING) trial randomized patients to 6 months of steroids or placebo and was terminated early after an interim analysis revealed a high risk of infectious serious adverse events including lethal Pneumocystis jirovecii pneumonia. ${ }^{12}$ There was a significant reduction in the risk of a $40 \%$ decline in eGFR or ESKD in the steroid group. The kidney function loss in the control group was 4 times faster in the TESTING trial than in the STOP-IgAN trial, suggesting a higher-risk population and/or differences in supportive therapy. In TESTING, the beneficial impact of steroids was similar in patients with eGFR $>$ or $<50 \mathrm{ml} / \mathrm{min}$ per $/ 1.73 \mathrm{~m}^{2}$. This finding is consistent with analyses of other clinical trials that also showed a benefit of immunosuppression at lower eGFR but with an increased risk of adverse events. ${ }^{77,83}$ Future guideline recommendations (Supplementary Table S1) will need to include an assessment of the relative risks and benefits of steroids in individual patients over a broader range of eGFR, with careful consideration of infections and prophylaxis.

Although previous studies suggested mycophenolate mofetil (MMF) was not effective for treatment of IgAN, ${ }^{84,85} 2$ recent trials add conflicting information. A mostly Caucasian trial was stopped early for futility because there was no MMF effect on the proteinuria-based primary outcome. ${ }^{86}$ However, a Chinese trial randomized patients to 6 months of full dose steroids or lower dose steroids with MMF. ${ }^{87}$ After 1 year, 


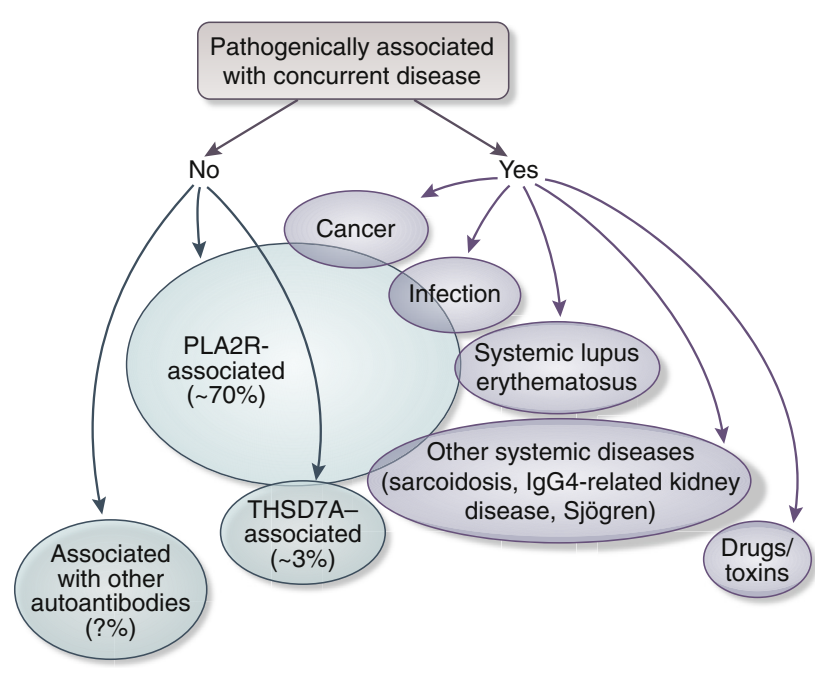

Figure 2 | Proposed categorization of membranous nephropathy. With the discovery of antibody target antigens in a majority of patients with membranous nephropathy, a disease categorization is emerging based on the detection and serotype of these antibodies. This figure suggests a categorization based on the current knowledge of such antibodies. The relative size of the disease categories and their overlap is approximate (not to scale). Despite the specificity of anti-M-type phospholipase A2 receptor (anti-PLA2R) antibodies for primary membranous nephropathy, the presence of such antibodies does not rule out the concurrence of infection, malignancy, or other disease processes and does not obviate the need for an infectious work-up and age-appropriate cancer screening. Analysis of the frequency of detectable anti-PLA2R antibodies in patients with membranous nephropathy and other diseases is low and is still evolving with additional research. Recent studies have reported on the detection of anti-PLA2R antibodies in a substantial minority of patients with hepatitis infection or with sarcoidosis. These findings do not necessarily imply a pathogenic link between the concurrent disease and membranous nephropathy. Emerging data suggest a possible association between thrombospondin type 1 domaincontaining 7A (THSD7A) antibodies and cancer.

complete proteinuria remission was similar between the 2 groups, but with fewer steroid-related adverse events in those treated with MMF. This study reintroduces the possibility that MMF may be effective for IgAN; however, there was very infrequent use of RAS-blockade; it was not a multiethnic study population and the follow-up duration was too short to evaluate an effect on kidney function. Further studies will be required before MMF can be considered for treatment in IgAN. Both RAS-blockers and MMF may affect pregnancy adversely and patients will need to understand this and exercise appropriate use of contraception when being treated.

Tonsillectomy remains a controversial therapy for IgAN. A Japanese trial compared tonsillectomy with steroids versus steroids alone and found marginally higher proteinuria reduction in the tonsillectomy group but no impact on eGFR over 12 months. ${ }^{88}$ Only one-half of the patients received RAS blockade, and there was no long-term follow-up to evaluate changes in eGFR. In a European cohort, tonsillectomy patients were propensity-score matched to control patients with no benefit in change of GFR or proteinuria. ${ }^{89}$ Therefore, tonsillectomy may only be considered in IgAN patients with recurrent tonsillitis.
Although observational data suggest that IgAN incidence and outcome may differ between Caucasians and Asians, ${ }^{90-92}$ there is currently insufficient evidence to suggest that treatment approaches should differ by ethnicity. Possibly, systematic differences in study populations, other than ethnicity, may explain different treatment responses. ${ }^{86,93}$ Multiethnic trials, such as the ongoing TESTING Low Dose trial (ClinicalTrials.gov NCT01560052), are evaluating this issue further.

\section{Future studies}

Trials of rituximab and tacrolimus have yielded negative results. ${ }^{94,95}$ Current trials address the spleen tyrosine kinase inhibitor fostamatinib, and the B-cell activating factor and a proliferation inducing ligand blocker atacicept (Figure 1). A pilot study of the proteasome inhibitor bortezomib has just been completed. Future multiethnic trials of other pharmacologic agents should incorporate therapeutic drug level monitoring to help determine whether ethnic differences in outcome may be related to pharmacokinetics versus differential disease response.

\section{MEMBRANOUS NEPHROPATHY}

Membranous nephropathy is characterized by subepithelial glomerular immune complexes. The discovery of podocyte antigens to which circulating antibodies are directed has been a major breakthrough. ${ }^{96,97}$ This, and the reports of clinical studies and trials mandate revisiting nearly all of 2012 KDIGO membranous nephropathy recommendations ${ }^{1}$ (Supplementary Table S2).

\section{Terminology}

The discovery of antibodies against intrinsic podocyte antigens (PLA2R and thrombospondin-like domain 7A [THSD7A]) established that membranous nephropathy is an autoimmune disease. Emerging data point to the diagnostic, prognostic, and disease-monitoring value of measuring antiPLA2R antibodies levels. ${ }^{8}$ This introduced a categorization of membranous nephropathy based on the detectable autoantibodies versus nephropathy not associated with either antibody. Membranous nephropathy associated with other disease processes (infections, systemic lupus erythematosus, sarcoidosis, malignancies) constitutes a separate category (Figure 2).

\section{Pathogenesis}

Antibodies against PLA2R and THSD7A are present in 50\% to $80 \%$ and $2 \%$ to $4 \%$ of patients with membranous nephropathy, respectively. The 2 serotypes coexist only occasionally. PLA2R antibodies are uncommon in patients with membranous nephropathy associated with malignancies. Conversely, cancer may be more common among patients with THSD7A antibodies, but the data are still insufficient to direct malignancy screening approaches in membranous nephropathy. PLA2R-associated membranous nephropathy is linked to genetic polymorphisms in the PLA2R gene, which 


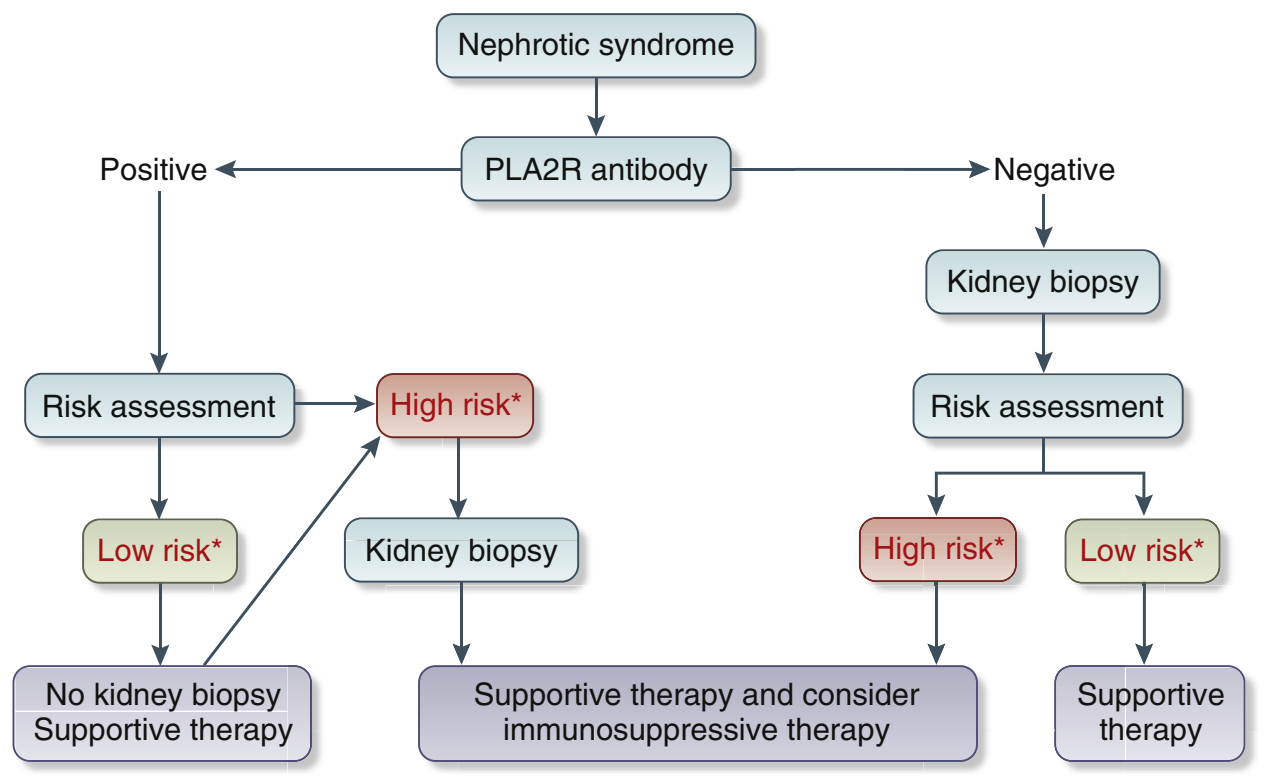

Figure 3 | Proposed algorithm for the diagnosis of membranous nephropathy. *See Table 2 for definitions of low and high risk. PLA2R, Mtype phospholipase A2 receptor.

provides additional evidence of the pathogenic role of this autoantibody. ${ }^{98,99}$

\section{Biomarkers: diagnosis and prediction of prognosis}

Role of the kidney biopsy in diagnosis. Because PLA2R antibodies predict membranous nephropathy with high specificity, a kidney biopsy may not be needed in antiPLA2R-positive patients with a low risk of disease progression and/or a high risk of biopsy-related morbidity ${ }^{5,100}$ (Figure 3, Table 2). When immunosuppressive therapy is contemplated, performing a kidney biopsy is still recommended to exclude another concomitant process and to estimate the extent of chronic fibrosis. A kidney biopsy is especially indicated in cases of nephrotic syndrome and acute kidney injury because it may identify cases of membranous nephropathy with crescentic GN (anti-glomerular basement membrane or antineutrophil cytoplasmic antibody-associated) even in cases that are positive for anti-PLA2R. In antiPLA2R-negative patients, a kidney biopsy is needed to diagnose membranous nephropathy. In such patients, it is important to look at whether PLA2R staining is present in the glomeruli, because this will allow identification of patients with PLA2R-associated membranous nephropathy. In selected cases of membranous nephropathy, it may be important to look at IgG subclasses in the kidney biopsy, with IgG1dominant staining being suggestive of secondary causes. The specificity of THSD7A antibodies in diagnosing membranous nephropathy is not well established.

The presence of PLA2R antibodies does not allow exclusion of a concurrent infection or cancer.

Risk-stratification. Patients with membranous nephropathy and subnephrotic proteinuria have excellent long-term renal survival and do not need immunosuppression. Among patients with nephrotic range proteinuria, disease severity varies and prognosis ranges from spontaneous remission to severe nephrotic syndrome and progression to ESKD. In such patients, the risks of immunosuppression should not exceed the short-term risks of nephrotic syndrome. The current risk stratification of patients who need treatment ( $>6$ months of proteinuria $>4 \mathrm{~g} / \mathrm{d}$ ) lacks specificity, as a substantial proportion of such patients may still develop spontaneous remission. ${ }^{101}$ Models that use other cutoff points or that include the serial measurement of urinary low-molecularweight proteins, serum albumin, and eGFR may allow better assessment of the risk of disease complications and/or progression. Emerging data point to the prognostic value of quantitatively measuring PLA2R antibody levels and possibly

Table 2 | Factors associated with the risk of progressive loss of kidney function in patients with membranous nephropathy

\begin{tabular}{ll}
\hline Low risk & \multicolumn{1}{c}{ High risk } \\
\hline Proteinuria & - Serum creatinine $>1.5 \mathrm{mg} / \mathrm{dl}(133 \mu \mathrm{mol} / \mathrm{l})$ \\
$<3.5 \mathrm{~g} / \mathrm{d}$ & - Decrease in eGFR by $\geq 20 \%$ over any time period \\
& during the preceding 12 months not explained \\
& otherwise $^{\mathrm{a}}$ \\
& - Proteinuria $>8 \mathrm{~g} / \mathrm{d}$ for $>6 \mathrm{mo}$ \\
& - Presence of low-molecular-weight proteinuria \\
& - Urine $\mathrm{lgG}>250 \mathrm{mg} / 24 \mathrm{~h}$ \\
& - PLA2R antibody levels and evolution ${ }^{\mathrm{b}}$ \\
\hline
\end{tabular}

eGFR, estimated glomerular filtration rate; PLA2R, M-type phospholipase A2 receptor.

The table lists factors that have been associated with increased risk of disease progression. The presence of any of these risk factors may suffice to consider immunosuppressive therapy but risk increases if several factors are present. Treating physicians should take these factors and the patient's symptoms, comorbidities, and risks of complications into consideration when determining the timing and choice of therapy.

a eGFR decline not attributable to causes other than membranous nephropathy such as initiation of renin-angiotensin system blockers or intravascular volume depletion. ${ }^{b}$ Insufficient data are currently available to determine the cutoff level of PLA2R antibody associated with increased risk of progression. 
Table 3 | PLA2R antibodies: predictor of disease course and treatment response

\begin{tabular}{|c|c|c|c|c|}
\hline Author and study description & PLA2R Ab level & $\begin{array}{l}\text { Patients with } \\
\text { complete or partial } \\
\text { remission (\%) }\end{array}$ & $P$ value or HRs & $\begin{array}{l}\text { PLA2R assay } \\
\text { method }\end{array}$ \\
\hline $\begin{array}{l}\text { Hofstra } 2012^{112} \\
\text { Analysis of spontaneous remissions }\end{array}$ & $\begin{array}{c}41-175 \mathrm{U} / \mathrm{ml} \\
176-610 \mathrm{U} / \mathrm{ml} \\
>610 \mathrm{U} / \mathrm{ml}\end{array}$ & $\begin{array}{c}38 \% \\
31 \% \\
4 \%\end{array}$ & $P<0.01$ & ELISA: in house \\
\hline $\begin{array}{l}\text { Ruggenenti } 2015^{111} \\
\text { All patients treated with rituximab }\end{array}$ & $\begin{array}{l}\text { 14-86 RU/ml } \\
87-204 \mathrm{RU} / \mathrm{ml} \\
>204 \mathrm{RU} / \mathrm{ml}\end{array}$ & $\begin{array}{l}82 \% \\
59 \% \\
37 \%\end{array}$ & $\begin{array}{c}\text { HR: } 4.2 \text { (95\% Cl: } 1.9-9.2 ; P<0.0001)^{\mathrm{a}} \\
\text { HR: } 2.3(95 \% \mathrm{Cl}: 1.0-5.2 \\
P=0.048)^{\mathrm{a}} \\
1\end{array}$ & ELISA: Eurolmmune \\
\hline $\begin{array}{l}\text { Dahan } 2017^{101} \\
\text { Randomized controlled trial of rituximab }\end{array}$ & $\begin{array}{l}<275 \mathrm{RU} / \mathrm{ml} \\
>275 \mathrm{RU} / \mathrm{ml}\end{array}$ & $\begin{array}{l}43 \%^{b} \\
20 \%^{b}\end{array}$ & OR: $3.5(95 \% \mathrm{Cl}: 1.1-10.7 ; P=0.03)^{\mathrm{C}}$ & ELISA: Eurolmmune \\
\hline \multicolumn{5}{|c|}{$\begin{array}{l}\text { Ab, antibody; } \mathrm{Cl} \text {, confidence interval; ELISA, enzyme linked immunosorbent assay; HR, hazard ratio(s); OR, odds ratio; PLA2R, M-type phospholipase A2 receptor; RU, relative } \\
\text { unit(s). } \\
\text { Complete remission was defined as proteinuria }<0.2,<0.3 \text {, or }<0.5 \mathrm{~g} / \mathrm{d} \text {; partial remission as }<3.0 \mathrm{~g} / \mathrm{d} \text { with } \geq 50 \% \text { reduction from baseline. Spontaneous remission was defined } \\
\text { as complete or partial remission without any immunosuppressive therapy. } \\
{ }^{a} \text { Compared with highest tertile of baseline anti-PLA2R level ( }>204 \mathrm{RU} / \mathrm{ml} \text { ). } \\
\text { bersonal communication. } \\
\text { 'By multivariate analysis, odds ratio of complete or partial remission at last follow-up (median: } 17.0 \text { [interquartile range: } 12.5-24.0 \text { ] months) compared with group with } \\
\text { baseline anti-PLA2R }>275 \mathrm{RU} / \mathrm{ml} \text {, independent from treatment group (nonimmunosuppressive antiproteinuric therapy with or without rituximab), age, sex, baseline pro- } \\
\text { teinuria, serum albumin, and creatinine. }\end{array}$} \\
\hline
\end{tabular}

qualitatively defining the spread of their target epitopes. ${ }^{102,103}$ In PLA2R-positive patients, low antibody levels appear to predict a greater likelihood of spontaneous remission than high levels. Conversely, patients with antibodies targeting 2 or 3 target epitope domains may be less likely to develop a spontaneous remission.

A recent study showed that changes in PLA2R antibody levels during follow-up were correlated with changes in proteinuria. ${ }^{104}$ Because this study included treated patients, data are lacking on the value of monitoring the trend of PLA2R antibody levels prior to immunosuppressive therapy to guide the decision to initiate such treatment or the choice of therapeutic agents.

\section{Treatment}

Besides preservation of kidney function and proteinuria remission, future goals of treatment should include improvement of patient-related outcomes and quality-of-life measures (for which validated instruments should be developed) and prevention of cardiovascular and thromboembolic events, ${ }^{45}$ infections, and patient mortality.

There is consensus that immunosuppression should be started in the presence of decreasing GFR or, in particular, severe life-threatening nephrotic syndrome. In patients with minimal symptoms and preserved kidney function, delaying immunotherapy while maximizing treatment of proteinuria, hypertension, and hyperlipidemia for up to 3 years may be acceptable. ${ }^{105}$ The availability of less toxic treatments may lead to earlier initiation of immunotherapy to allow more rapid disappearance of symptoms of nephrotic syndrome. Apart from small kidney size there is no other threshold for which treatment is deemed futile. Therapy can stabilize even patients with eGFR $<30 \mathrm{ml} / \mathrm{min}$ per $1.73 \mathrm{~m}^{2}$. A kidney biopsy is valuable in identifying acute kidney injury or assessing the severity of fibrosis.

\section{Treatment with immunosuppressive agents}

All patients should undergo screening for infections and an age-appropriate screening for malignancies prior to commencing immunosuppressive therapy.

Alkylating agents remain the only agents proven effective in preventing ESKD or death. ${ }^{106}$ Given their toxicity, they should only be prescribed by experienced physicians and restricted to patients at high risk of progression. Current and previous smokers may be at particularly increased risk for subsequent bladder or lung cancer associated with exposure to cytotoxic agents. Special consideration should likewise be given to patients of childbearing age because of the risk of infertility associated with these agents. Historically, treatment with an alkylating agent had been cyclical and accompanied by pulses of i.v. methylprednisolone. Other regimens are used in clinical practice, including daily cyclophosphamide and omission of pulses of methylprednisolone.

Other immunosuppressive agents only used proteinuria reduction as the endpoint. Therapy with calcineurin inhibitors induced remissions with similar frequency as cyclophosphamide but was associated with a higher relapse rate. ${ }^{107,108}$ Continued daily use of a calcineurin inhibitors may maintain remission; however, the consequences of longterm therapy are unknown. In 1 controlled trial, chlorambucil, but not cyclosporine, reduced eGFR loss in membranous nephropathy with renal insufficiency. ${ }^{109}$

In the Evaluate Rituximab Treatment for Idiopathic Membranous Nephropathy (GEMRITUX) study, rituximab was more effective than placebo in inducing remissions after 17 months. ${ }^{101}$ The nonresponse rate to rituximab was approximately $35 \%$. A recent retrospective propensity- 
matched cohort study suggested lower partial remission rates with rituximab versus cyclophosphamide. ${ }^{110}$ Measurement of PLA2R antibodies might aid in predicting treatment response (Table 3). ${ }^{111}$ The choice of first-line therapy therefore still awaits direct head-to-head trials. It is likely that the choice of therapy may be determined by improved risk-stratification models.

Disease monitoring. PLA2R antibody levels may be valuable for monitoring treatment and follow-up. Complete remissions are almost always associated with the disappearance of PLA2R antibodies. Although declining antibody levels may precede clinical remission, it is currently unclear to what extent a decrease predicts a subsequent remission. Therefore, serial monitoring of PLA2R antibodies during treatment requires further study. During remission of proteinuria, there is no evidence to support preemptive therapy based on rising antibody levels alone. Still, measuring PLA2R antibodies in patients with a recurrence or worsening of proteinuria should help distinguish between relapse and other causes of proteinuria. Persistent anti-PLA2R antibodies prior to kidney transplantation are associated with an increased risk of recurrence of membranous nephropathy in the allograft. There are insufficient data to assess whether a kidney transplant should be delayed until the antibodies become negative and for how long. Conditions under which a repeat biopsy or screening workup for infections, malignancy, or other causes of nephrotic syndrome should be done are not well defined.

\section{Future studies}

While anti-PLA2R antibody assays are reasonably comparable for diagnostic purposes, they quantitatively differ. Any riskstratification or disease-monitoring model based on antibody levels will require harmonization and calibration of tests. To what extent and in what capacity antibody levels may be used in defining surrogate endpoints in clinical trials requires formal evaluation.

Additional research is needed to develop more accurate risk-stratification models that incorporate other biomarkers of disease in addition to proteinuria-including qualitative and quantitative measures of autoantibodies.

We expect data from the Membranous Nephropathy Trial of Rituximab (MENTOR) study (which compared rituximab vs. cyclosporine) in the short term. The report of the Sequential Therapy With Tacrolimus and Rituximab in Primary Membranous Nephropathy (STARMEN) study (which compares tacrolimus and rituximab vs. the cyclical cyclophosphamide and corticosteroids "Ponticelli" regimen) is expected in 2019. Studies using combinations of existing drugs and the evaluation of novel agents directed at different immunological targets may improve the frequency and/or duration of complete remissions.

With respect to trial design, complete remission (proteinuria $<0.3 \mathrm{~g} / \mathrm{d}$ combined with stable GFR) may be used as a surrogate endpoint. Partial remission $(50 \%$ reduction of proteinuria to a level $<3.5 \mathrm{~g} / \mathrm{d}$ ) should be evaluated as a surrogate endpoint. The role of serum albumin in defining partial remission needs further formal evaluation, as well as harmonization of the serum albumin assays.

\section{CONCLUSIONS}

While old problems such as the best way of assessing kidney function, kidney disease activity, and proteinuria still linger in nephrology, major progress has been made in our understanding of disease pathogenesis in IgAN and membranous nephropathy. The number of randomized trials in these diseases has grown steadily and several phase 3 trials are currently underway. Recent attempts to define surrogate outcomes, such as full remission in membranous nephropathy, will certainly further bolster this field.

\section{APPENDIX \\ Other Conference Participants}

Sharon G. Adler, USA; Charles E. Alpers, USA; Isabelle Ayoub, USA; Arvind Bagga, India; Jonathan Barratt, UK; Dawn J. Caster, USA; Daniel T.M. Chan, Hong Kong; Anthony Chang, USA; Jason Chon Jun Choo, Singapore; H. Terence Cook, UK; Rosanna Coppo, Italy; Fernando C. Fervenza, USA; Agnes B. Fogo, USA; Jonathan G. Fox, UK; Keisha L. Gibson, USA; Richard J. Glassock, USA; David Harris, Australia; Elisabeth M. Hodson, Australia; Elion Hoxha, Germany; Kunitoshi Iseki, Japan; J. Charles Jennette, USA; Vivekanand Jha, India; David W. Johnson, Australia; Shinya Kaname, Japan; Ritsuko Katafuchi, Japan; A. Richard Kitching, Australia; Richard A. Lafayette, USA; Philip K.T. Li, Hong Kong; Adrian Liew, Singapore; Jicheng Lv, China; Ana Malvar, Argentina; Shoichi Maruyama, Japan; Juan Manuel Mejía-Vilet, Mexico; Marcus J. Moeller, Germany; Chi Chiu Mok, Hong Kong; Carla M. Nester, USA; Eisei Noiri, Japan; Michelle M.

O'Shaughnessy, USA; Seza Özen, Turkey; Samir M. Parikh, USA; Hyeong-Cheon Park, Korea; Chen Au Peh, Australia; William F. Pendergraft, USA; Matthew C. Pickering, UK; Evangéline Pillebout, France; Jai Radhakrishnan, USA; Manish Rathi, India; Dario Roccatello, Italy; Pierre Ronco, France; William E. Smoyer, USA; Vladimír Tesař, Czech Republic; Joshua M. Thurman, USA; Hernán Trimarchi, Argentina; Marina Vivarelli, Italy; Giles D. Walters, Australia; Angela YeeMoon Wang, Hong Kong; Scott E. Wenderfer, USA

\section{DISCLOSURE}

JF declared having received consultancy fees from Amgen, Alnylam, Bayer, Boehringer Ingelheim, Calliditas, Inositec, Novo Nordisk, Omeros, and Vifor; speaker honoraria from Amgen and Vifor; and travel support from Boehringer Ingelheim. DCC declared having received consultancy fees from Alnylam, Calliditas, ChemoCentryx, Dimerix, Mallinckrodt, Novartis, and Rigel; and research support from Genentech and National Institute of Diabetes, Digestive, and Kidney Diseases. JJH declared having received consultancy fees from Aurinia, Dimerix, and Variant. PHN declared having received research support from Immune Tolerance Network. SCWT declared having received consultancy fees from AstraZeneca, Boehringer Ingelheim, and Sanofi. JFMW declared having received research support from Dutch Kidney Foundation and European Union FP7 programme (EUrenOmics); and future research support from Achillion and ChemoCentryx. DCW declared having received consultancy fees from Akebia, AstraZeneca, Amgen, Boehringer Ingelheim,

GlaxoSmithKline, Janssen, and Vifor Fresenius; speaker honoraria from Amgen and Vifor Fresenius; and research support from AstraZeneca. WCW declared having received consultancy fees from Akebia, AMAG, Amgen, AstraZeneca, Bayer, Daichii-Sankyo, Relypsa, and ZS Pharma; speaker honoraria from FibroGen; and research support from National Institutes of Health. BHR declared having received consultancy fees from Alexion, Aurinia, Biogen, Biomarin, Bristol-Myers Squibb, ChemoCentryx, EMD Serono, Frazier Life Sciences, Genentech, Gilead, Lupus Foundation of America, Mallinckrodt, Medlmmune, Novartis, Pharmalink, Ra Pharmaceuticals, Retrophin, and Rigel; and travel support from American Society of Nephrology, Aurinia, Biogen, Budapest Nephrology School, Childhood Arthritis and Rheumatology Research Alliance, ChemoCentryx, Congress on SLE (Australia), Central Society for Clinical and Translational Research-Midwestern American Federation for Medical Research, CureGN, European League Against Rheumatism Congress and Portuguese Congress, KDIGO, MENTOR (Multicenter Randomized Controlled Trial of Rituximab), Office of Minority Health Impact for Lupus, Pharmalink, Ra 
Pharmaceuticals, Retrophin, and UpToDate. All other authors declared no competing interests.

\section{ACKNOWLEDGMENTS}

The conference was sponsored by KDIGO and supported in part by unrestricted educational grants from Achillion, Aurinia

Pharmaceuticals, Calliditas Therapeutics, ChemoCentryx, Chugai, Expedition Therapeutics, Gilead, Goldfinch Bio, Kyowa Kirin, Mallinckrodt Pharmaceuticals, Novartis, Omeros, Sanofi Genzyme, and Vifor Fresenius Medical Care Renal Pharma.

\section{SUPPLEMENTARY MATERIAL}

Table S1. 2012 Kidney Disease: Improving Global Outcomes (KDIGO) Glomerulonephritis (GN) guideline recommendations related to $\lg \mathrm{A}$ nephropathy: Need to be revisited?

Table S2. 2012 Kidney Disease: Improving Global Outcomes (KDIGO) Glomerulonephritis (GN) guideline recommendations related to membranous nephropathy (MN): Need to be revisited? Supplementary material is linked to the online version of the paper at www.kidney-international.org.

\section{REFERENCES}

1. Kidney Disease: Improving Global Outcomes (KDIGO) Glomerulonephritis Work Group. KDIGO clinical practice guideline for glomerulonephritis. Kidney Int Suppl. 2012;2:139-274.

2. Sethi S, D'Agati VD, Nast CC, et al. A proposal for standardized grading of chronic changes in native kidney biopsy specimens. Kidney Int. 2017;91:787-789.

3. D'Agati VD, Mengel M. The rise of renal pathology in nephrology: structure illuminates function. Am J Kidney Dis. 2013;61:1016-1025.

4. Larsen $\mathrm{CP}$, Messias NC, Silva FG, et al. Determination of primary versus secondary membranous glomerulopathy utilizing phospholipase A2 receptor staining in renal biopsies. Mod Pathol. 2013;26:709-715.

5. Dai H, Zhang H, He Y. Diagnostic accuracy of PLA2R autoantibodies and glomerular staining for the differentiation of idiopathic and secondary membranous nephropathy: an updated meta-analysis. Sci Rep. 2015;5:8803.

6. Hodgin JB, Bitzer M, Wickman L, et al. Glomerular aging and focal global glomerulosclerosis: a podometric perspective. J Am Soc Nephrol. 2015;26:3162-3178.

7. Beck LH Jr, Fervenza FC, Beck DM, et al. Rituximab-induced depletion of anti-PLA2R autoantibodies predicts response in membranous nephropathy. J Am Soc Nephrol. 2011;22:1543-1550.

8. De Vriese AS, Glassock RJ, Nath KA, et al. A proposal for a serologybased approach to membranous nephropathy. J Am Soc Nephrol. 2017;28:421-430.

9. Sethi S, Glassock RJ, Fervenza FC. Focal segmental glomerulosclerosis: towards a better understanding for the practicing nephrologist. Nephrol Dial Transplant. 2015;30:375-384.

10. Hogan MC, Reich HN, Nelson PJ, et al. The relatively poor correlation between random and 24-hour urine protein excretion in patients with biopsy-proven glomerular diseases. Kidney Int. 2016;90:10801089.

11. Reich HN, Troyanov S, Scholey JW, et al. Remission of proteinuria improves prognosis in IgA nephropathy. J Am Soc Nephrol. 2007;18:3177-3183.

12. Lv J, Zhang H, Wong MG, et al. Effect of oral methylprednisolone on clinical outcomes in patients with IgA nephropathy: the TESTING randomized clinical trial. JAMA. 2017;318:432-442.

13. Hebert LA, Birmingham DJ, Shidham G, et al. Random spot urine protein/creatinine ratio is unreliable for estimating 24-hour proteinuria in individual systemic lupus erythematosus nephritis patients. Nephron Clin Pract. 2009;113:c177-c182.

14. Rizk DV, Meier D, Sandoval RM, et al. A novel method for rapid bedside measurement of GFR. J Am Soc Nephrol. 2018;29:1609-1613.

15. Ix JH, Wassel $C L$, Stevens $L A$, et al. Equations to estimate creatinine excretion rate: the CKD epidemiology collaboration. Clin J Am Soc Nephrol. 2011;6:184-191.

16. Gao A, Cachat F, Faouzi M, et al. Comparison of the glomerular filtration rate in children by the new revised Schwartz formula and a new generalized formula. Kidney Int. 2013;83:524-530.

17. Schwartz GJ, Work DF. Measurement and estimation of GFR in children and adolescents. Clin J Am Soc Nephrol. 2009:4:1832-1843.
18. Branten AJ, Vervoort G, Wetzels JF. Serum creatinine is a poor marker of GFR in nephrotic syndrome. Nephrol Dial Transplant. 2005;20:707-711.

19. Stevens LA, Levey AS. Measured GFR as a confirmatory test for estimated GFR. J Am Soc Nephrol. 2009;20:2305-2313.

20. Inker LA, Tonelli M, Hemmelgarn BR, et al. Comparison of concurrent complications of CKD by 2 risk categorization systems. Am J Kidney Dis. 2012;59:372-381.

21. Tang LL, Liu A, Chen Z, et al. Nonparametric ROC summary statistics for correlated diagnostic marker data. Stat Med. 2013;32:2209-2220.

22. Geetha D, Seo P, Ellis $C$, et al. Persistent or new onset microscopic hematuria in patients with small vessel vasculitis in remission: findings on renal biopsy. J Rheumatol. 2012;39:1413-1417.

23. Sevillano AM, Gutierrez E, Yuste $C$, et al. Remission of hematuria improves renal survival in IgA nephropathy. J Am Soc Nephrol. 2017;28: 3089-3099.

24. Levey AS, Inker LA, Matsushita K, et al. GFR decline as an end point for clinical trials in CKD: a scientific workshop sponsored by the National Kidney Foundation and the US Food and Drug Administration. Am J Kidney Dis. 2014;64:821-835.

25. Thompson A, Cattran DC, Blank M, et al. Complete and partial remission as surrogate end points in membranous nephropathy. J Am Soc Nephrol. 2015;26:2930-2937.

26. Cattran DC, Kim ED, Reich H, et al. Membranous nephropathy: quantifying remission duration on outcome. J Am Soc Nephrol. 2017;28: 995-1003.

27. Morrell GR, Zhang JL, Lee VS. Magnetic resonance imaging of the fibrotic kidney. J Am Soc Nephrol. 2017;28:2564-2570.

28. Hebert LA, Wilmer WA, Falkenhain ME, et al. Renoprotection: one or many therapies? Kidney Int. 2001;59:1211-1226.

29. Bertram JF, Douglas-Denton RN, Diouf B, et al. Human nephron number: implications for health and disease. Pediatr Nephrol. 2011;26:1529-1533.

30. Ricardo AC, Goh V, Chen J, et al. Association of sleep duration, symptoms, and disorders with mortality in adults with chronic kidney disease. Kidney Int Rep. 2017;2:866-873.

31. Morales $E$, Valero MA, Leon M, et al. Beneficial effects of weight loss in overweight patients with chronic proteinuric nephropathies. Am J Kidney Dis. 2003;41:319-327.

32. Afshinnia F, Wilt TJ, Duval S, et al. Weight loss and proteinuria: systematic review of clinical trials and comparative cohorts. Nephrol Dial Transplant. 2010;25:1173-1183.

33. Kittiskulnam $\mathrm{P}$, Kanjanabuch $\mathrm{T}$, Tangmanjitjaroen $\mathrm{K}$, et al. The beneficial effects of weight reduction in overweight patients with chronic proteinuric immunoglobulin a nephropathy: a randomized controlled trial. J Ren Nutr. 2014;24:200-207.

34. Cattran DC, Reich HN, Beanlands HJ, et al. The impact of sex in primary glomerulonephritis. Nephrol Dial Transplant. 2008;23:2247-2253.

35. Sampson MG, Hodgin JB, Kretzler M. Defining nephrotic syndrome from an integrative genomics perspective. Pediatr Nephrol. 2015;30:51-63.

36. Preston R, Stuart HM, Lennon R. Genetic testing in steroid-resistant nephrotic syndrome: why, who, when and how? [e-pub ahead of print]. Pediatr Nephrol. https://doi.org/10.1007/s00467-017-3838-6. Accessed December 15, 2018.

37. Agarwal R. Resistant hypertension and the neglected antihypertensive: sodium restriction. Nephrol Dial Transplant. 2012;27:4041-4045.

38. Bibbins-Domingo K, Chertow GM, Coxson PG, et al. Projected effect of dietary salt reductions on future cardiovascular disease. $N$ Engl J Med. 2010;362:590-599.

39. Voskamp PWM, Dekker FW, van Diepen M, et al. Effect of dual compared to no or single renin-angiotensin system blockade on risk of renal replacement therapy or death in predialysis patients: PREPARE-2 study. J Am Soc Hypertens. 2017;11:635-643.

40. Joseph JJ, Echouffo-Tcheugui JB, Kalyani RR, et al. Aldosterone, renin, cardiovascular events, and all-cause mortality among African Americans: the Jackson Heart Study. JACC Heart Fail. 2017;5:642-651.

41. Petrykiv $\mathrm{SI}$, Laverman GD, Persson F, et al. Pooled analysis of multiple crossover trials to optimize individual therapy response to reninangiotensin-aldosterone system intervention. Clin J Am Soc Nephrol. 2017;12:1804-1813.

42. Antlanger M, Bernhofer S, Kovarik JJ, et al. Effects of direct renin inhibition versus angiotensin II receptor blockade on angiotensin profiles in nondiabetic chronic kidney disease. Ann Med. 2017;49:525-533.

43. Rajasekeran $\mathrm{H}$, Reich $\mathrm{HN}$, Hladunewich MA, et al. Dapagliflozin in focal segmental glomerulosclerosis: a combined human-rodent pilot study. Am J Physiol Renal Physiol. 2018;314:F412-F422. 
44. Markossian T, Burge N, Ling B, et al. Controversies regarding lipid management and statin use for cardiovascular risk reduction in patients with CKD. Am J Kidney Dis. 2016;67:965-977.

45. Lee T, Derebail VK, Kshirsagar AV, et al. Patients with primary membranous nephropathy are at high risk of cardiovascular events. Kidney Int. 2016;89:1111-1118.

46. Sabatine MS, Giugliano RP, Keech AC, et al. Evolocumab and clinical outcomes in patients with cardiovascular disease. N Engl J Med. 2017;376:1713-1722.

47. Kotur-Stevuljevic J, Peco-Antic A, Spasic S, et al. Hyperlipidemia, oxidative stress, and intima media thickness in children with chronic kidney disease. Pediatr Nephrol. 2013;28:295-303.

48. Haynes R, Lewis D, Emberson J, et al. Effects of lowering LDL cholesterol on progression of kidney disease. J Am Soc Nephrol. 2014;25:1825-1833.

49. Lee T, Biddle AK, Lionaki S, et al. Personalized prophylactic anticoagulation decision analysis in patients with membranous nephropathy. Kidney Int. 2014;85:1412-1420.

50. Barbour SJ, Greenwald A, Djurdjev O, et al. Disease-specific risk of venous thromboembolic events is increased in idiopathic glomerulonephritis. Kidney Int. 2012;81:190-195.

51. Stamellou E, Floege J. Novel oral anticoagulants in patients with chronic kidney disease and atrial fibrillation. Nephrol Dial Transplant. 2018;33: 1683-1689.

52. Cholongitas E, Haidich AB, Apostolidou-Kiouti F, et al. Hepatitis B virus reactivation in $\mathrm{HBsAg}$-negative, anti-HBc-positive patients receiving immunosuppressive therapy: a systematic review. Ann Gastroenterol. 2018;31:480-490.

53. National Renal Complement Therapeutics Centre. Guidelines for the prevention of meningococcal disease in adult patients receiving eculizumab for the treatment of atypical haemolytic uraemic syndrome. Available at: http://www.atypicalhus.co.uk/wp-content/ uploads/2017/07/Meningococcal-guidelines-adult1.pdf. Accessed April 17, 2018.

54. Perkovic V, Agarwal R, Fioretto P, et al. Management of patients with diabetes and CKD: conclusions from a "Kidney Disease: Improving Global Outcomes" (KDIGO) Controversies Conference. Kidney Int. 2016:90:1175-1183.

55. Ayme S, Bockenhauer D, Day S, et al. Common elements in rare kidney diseases: conclusions from a Kidney Disease: Improving Global Outcomes (KDIGO) Controversies Conference. Kidney Int. 2017;92: 796-808.

56. Gadegbeku CA, Gipson DS, Holzman LB, et al. Design of the Nephrotic Syndrome Study Network (NEPTUNE) to evaluate primary glomerular nephropathy by a multidisciplinary approach. Kidney Int. 2013;83: 749-756.

57. Ju W, Nair V, Smith S, et al. Tissue transcriptome-driven identification of epidermal growth factor as a chronic kidney disease biomarker. Sci Transl Med. 2015;7:316ra193.

58. Boyd JK, Cheung CK, Molyneux K, et al. An update on the pathogenesis and treatment of IgA nephropathy. Kidney Int. 2012;81: 833-843.

59. Yeo SC, Cheung CK, Barratt J. New insights into the pathogenesis of IgA nephropathy. Pediatr Nephrol. 2018;33:763-777.

60. Berthoux F, Suzuki H, Thibaudin L, et al. Autoantibodies targeting galactose-deficient $\lg A 1$ associate with progression of $\lg A$ nephropathy. J Am Soc Nephrol. 2012;23:1579-1587.

61. Yasutake J, Suzuki Y, Suzuki H, et al. Novel lectin-independent approach to detect galactose-deficient IgA1 in IgA nephropathy. Nephrol Dial Transplant. 2015;30:1315-1321.

62. Gharavi AG, Kiryluk K, Choi M, et al. Genome-wide association study identifies susceptibility loci for IgA nephropathy. Nat Genet. 2011;43: 321-327.

63. Fellstrom BC, Barratt J, Cook H, et al. Targeted-release budesonide versus placebo in patients with IgA nephropathy (NEFIGAN): a doubleblind, randomised, placebo-controlled phase 2b trial. Lancet. 2017;389: 2117-2127.

64. Suzuki H, Suzuki Y, Narita I, et al. Toll-like receptor 9 affects severity of IgA nephropathy. J Am Soc Nephrol. 2008;19:2384-2395.

65. Niu D, Gao Y, Xie L, et al. Genetic polymorphisms in TNFSF13 and FDX1 are associated with IgA nephropathy in the Han Chinese population. Hum Immunol. 2015;76:831-835.

66. McCarthy DD, Kujawa J, Wilson C, et al. Mice overexpressing BAFF develop a commensal flora-dependent, IgA-associated nephropathy. J Clin Invest. 2011;121:3991-4002.
67. Maillard N, Wyatt RJ, Julian BA, et al. Current understanding of the role of complement in IgA nephropathy. J Am Soc Nephrol. 2015;26: 1503-1512.

68. Xie J, Kiryluk K, Li Y, et al. Fine mapping implicates a deletion of CFHR1 and CFHR3 in protection from IgA nephropathy in Han Chinese. J Am Soc Nephrol. 2016;27:3187-3194.

69. Rosenblad T, Rebetz J, Johansson M, et al. Eculizumab treatment for rescue of renal function in IgA nephropathy. Pediatr Nephrol. 2014;29: 2225-2228.

70. Ring T, Pedersen BB, Salkus $G$, et al. Use of eculizumab in crescentic IgA nephropathy: proof of principle and conundrum? Clin Kidney J. 2015;8: 489-491.

71. Block GA, Whitaker S. Maintenance of remission following completion of OMS721 treatment in patients with IgA nephropathy (IGAN). Abstract SA-PO278. J Am Soc Nephrol. 2017;28:749-750.

72. Working Group of the International IgA Nephropathy Network and the Renal Pathology Society, Cattran DC, et al. The Oxford classification of IgA nephropathy: rationale, clinicopathological correlations, and classification. Kidney Int. 2009;76:534-545.

73. Working Group of the International IgA Nephropathy Network and the Renal Pathology Society, Roberts IS, et al. The Oxford classification of IgA nephropathy: pathology definitions, correlations, and reproducibility. Kidney Int. 2009;76:546-556.

74. Coppo R, Troyanov S, Bellur S, et al. Validation of the Oxford classification of IgA nephropathy in cohorts with different presentations and treatments. Kidney Int. 2014;86:828-836.

75. Barbour SJ, Espino-Hernandez G, Reich HN, et al. The MEST score provides earlier risk prediction in IgA nephropathy. Kidney Int. 2016;89: 167-175.

76. Haas M, Verhave JC, Liu ZH, et al. A multicenter study of the predictive value of crescents in IgA nephropathy. J Am Soc Nephrol. 2017;28: 691-701.

77. Tesar V, Troyanov S, Bellur S, et al. Corticosteroids in IgA nephropathy: a retrospective analysis from the VALIGA study. J Am Soc Nephrol. 2015;26:2248-2258.

78. Herzenberg $A M$, Fogo $A B$, Reich $H N$, et al. Validation of the Oxford classification of IgA nephropathy. Kidney Int. 2011;80: 310-317.

79. Espinosa M, Ortega R, Sanchez M, et al. Association of C4d deposition with clinical outcomes in IgA nephropathy. Clin J Am Soc Nephrol. 2014;9:897-904.

80. FDA-NIH Biomarker Working Group. BEST (Biomarkers, EndpointS, and other Tools) Resource. Silver Spring, MD; Bethesda, MD: US Food and Drug Administration; National Institutes of Health; 2016. Available at: https://www.ncbi.nlm.nih.gov/books/NBK326791/. Accessed May 1, 2018.

81. Rauen T, Eitner F, Fitzner $C$, et al. Intensive supportive care plus immunosuppression in IgA nephropathy. N Engl J Med. 2015;373:22252236.

82. Rauen $\mathrm{T}$, Fitzner $\mathrm{C}$, Eitner $\mathrm{F}$, et al. Effects of two immunosuppressive treatment protocols for IgA nephropathy. J Am Soc Nephrol. 2018;29: 317-325.

83. Sarcina C, Tinelli C, Ferrario F, et al. Changes in proteinuria and side effects of corticosteroids alone or in combination with azathioprine at different stages of IgA nephropathy. Clin J Am Soc Nephrol. 2016;11: 973-981.

84. Maes BD, Oyen R, Claes K, et al. Mycophenolate mofetil in IgA nephropathy: results of a 3-year prospective placebo-controlled randomized study. Kidney Int. 2004;65:1842-1849.

85. Frisch G, Lin J, Rosenstock J, et al. Mycophenolate mofetil (MMF) vs placebo in patients with moderately advanced IgA nephropathy: a double-blind randomized controlled trial. Nephrol Dial Transplant. 2005;20:2139-2145.

86. Hogg RJ, Bay RC, Jennette JC, et al. Randomized controlled trial of mycophenolate mofetil in children, adolescents, and adults with IgA nephropathy. Am J Kidney Dis. 2015;66:783-791.

87. Hou JH, Le WB, Chen N, et al. Mycophenolate mofetil combined with prednisone versus full-dose prednisone in IgA nephropathy with active proliferative lesions: a randomized controlled trial. Am J Kidney Dis. 2017:69:788-795.

88. Kawamura T, Yoshimura M, Miyazaki Y, et al. A multicenter randomized controlled trial of tonsillectomy combined with steroid pulse therapy in patients with immunoglobulin A nephropathy. Nephrol Dial Transplant. 2014;29:1546-1553. 
89. Feehally J, Coppo R, Troyanov S, et al. Tonsillectomy in a European cohort of 1,147 patients with IgA nephropathy. Nephron. 2016;132:15-24.

90. Barbour SJ, Cattran DC, Kim SJ, et al. Individuals of Pacific Asian origin with IgA nephropathy have an increased risk of progression to endstage renal disease. Kidney Int. 2013;84:1017-1024.

91. Szeto CC, Lai FM, To KF, et al. The natural history of immunoglobulin a nephropathy among patients with hematuria and minimal proteinuria. Am J Med. 2001;110:434-437.

92. Gutierrez E, Zamora I, Ballarin JA, et al. Long-term outcomes of IgA nephropathy presenting with minimal or no proteinuria. J Am Soc Nephrol. 2012;23:1753-1760.

93. Tang SC, Tang AW, Wong SS, et al. Long-term study of mycophenolate mofetil treatment in IgA nephropathy. Kidney Int. 2010;77:543-549.

94. Lafayette RA, Canetta PA, Rovin BH, et al. A randomized, controlled trial of rituximab in IgA nephropathy with proteinuria and renal dysfunction. J Am Soc Nephrol. 2017;28:1306-1313.

95. Yu MY, Kim YC, Chin HJ. Short-term anti-proteinuric effect of tacrolimus is not related to preservation of glomerular filtration rate during 5 yearfollow up period in IgA nephropathy. Abstract SA-PO272. J Am Soc Nephrol. 2017;28:748.

96. Beck LH Jr, Bonegio RG, Lambeau G, et al. M-type phospholipase A2 receptor as target antigen in idiopathic membranous nephropathy. N Engl J Med. 2009;361:11-21.

97. Tomas NM, Beck LH Jr, Meyer-Schwesinger C, et al. Thrombospondin type-1 domain-containing 7A in idiopathic membranous nephropathy. N Engl J Med. 2014;371:2277-2287.

98. Stanescu HC, Arcos-Burgos M, Medlar A, et al. Risk HLA-DQA1 and PLA(2)R1 alleles in idiopathic membranous nephropathy. N Engl J Med. 2011;364:616-626.

99. Cui Z, Xie L, Chen FJ, et al. MHC class II risk alleles and amino acid residues in idiopathic membranous nephropathy. J Am Soc Nephrol. 2017;28:1651-1664.

100. Du Y, Li J, He F, et al. The diagnosis accuracy of PLA2R-AB in the diagnosis of idiopathic membranous nephropathy: a meta-analysis. PLoS One. 2014;9:e104936.

101. Dahan K, Debiec H, Plaisier $E$, et al. Rituximab for severe membranous nephropathy: a 6-month trial with extended follow-up. J Am Soc Nephrol. 2017;28:348-358.
102. Hofstra JM, Wetzels JF. Phospholipase A2 receptor antibodies in membranous nephropathy: unresolved issues. J Am Soc Nephrol. 2014;25:1137-1139.

103. Seitz-Polski B, Debiec H, Rousseau A, et al. Phospholipase A2 receptor 1 epitope spreading at baseline predicts reduced likelihood of remission of membranous nephropathy. J Am Soc Nephrol. 2018;29:401-408.

104. Radice A, Trezzi B, Maggiore U, et al. Clinical usefulness of autoantibodies to M-type phospholipase A2 receptor (PLA2R) for monitoring disease activity in idiopathic membranous nephropathy (IMN). Autoimmun Rev. 2016;15:146-154.

105. Hofstra JM, Fervenza FC, Wetzels JF. Treatment of idiopathic membranous nephropathy. Nat Rev Nephrol. 2013;9:443-458.

106. van de Logt AE, Hofstra JM, Wetzels JF. Pharmacological treatment of primary membranous nephropathy in 2016. Expert Rev Clin Pharmacol. 2016;9:1463-1478.

107. Ramachandran R, Hn HK, Kumar V, et al. Tacrolimus combined with corticosteroids versus modified Ponticelli regimen in treatment of idiopathic membranous nephropathy: randomized control trial. Nephrology. 2016;21:139-146.

108. Qiu T, Zhang C, Zhao HW, et al. Calcineurin inhibitors versus cyclophosphamide for idiopathic membranous nephropathy: a systematic review and meta-analysis of 21 clinical trials. Autoimmun Rev. 2017;16:136-145.

109. Howman A, Chapman TL, Langdon MM, et al. Immunosuppression for progressive membranous nephropathy: a UK randomised controlled trial. Lancet. 2013;381:744-751.

110. van den Brand J, Ruggenenti P, Chianca A, et al. Safety of rituximab compared with steroids and cyclophosphamide for idiopathic membranous nephropathy. J Am Soc Nephrol. 2017;28: 2729-2737.

111. Ruggenenti P, Debiec H, Ruggiero B, et al. Anti-phospholipase A2 receptor antibody titer predicts post-rituximab outcome of membranous nephropathy. J Am Soc Nephrol. 2015;26:25452558.

112. Hofstra JM, Debiec H, Short CD, et al. Antiphospholipase A2 receptor antibody titer and subclass in idiopathic membranous nephropathy. J Am Soc Nephrol. 2012;23:1735-1743. 